\title{
LOS HACENDADOS Y RANCHEROS MAYAS DE YUCATÁN EN EL SIGLO XIX
}

\section{Laura Machuca Gallegos \\ Centro de Investigaciones y Estudios Superiores en Antropología Social}

Resumen: No sólo los grupos "blancos" y pudientes de la sociedad tuvieron haciendas, sino también los mayas. Al ser la hacienda una de las pocas actividades económicas productivas que se podían llevar a cabo en la península, algunos mayas (si bien son minoría) se volvieron propietarios, incluso tuvieron trabajadores adeudados; por tanto, no permanecieron al margen del desarrollo económico y participaron activamente de éste.

Así, en este trabajo nos ocupamos de los amos mayas, seguimos algunas de sus estrategias y reconstruimos sus lazos y sus relaciones. La principal fuente utilizada han sido documentos de carácter notarial, en particular los testamentos, de los cuales se han estudiado algunas variables como la de cónyuge, albacea testamentario y testigo.

Palabras clave: hacienda, ranchos, testamentos, siglo xix, Yucatán.

ABSTRACT: Haciendas were not exclusive for "white" powerful groups, since they were available for the Maya. Hacienda was one of the only productive economic activities in the peninsula, so the Maya (in spite of being a minority) became the owners. They even had debtor workers. They were not marginalized from economic development but rather participated actively in it.

This paper studies Maya masters by following some of their strategies and reconstructing both their binds and relations. Our main source are notarial documents, particularly testaments, where some variables like spouse, testamentary executor and witness are studied.

KeYwords: hacienda, ranchs, testaments, 19th Century, Yucatán.

RECEPCIÓN: 1 de octubre de 2008.

ACEPTACIÓN: 24 de mayo de 2010. 



\title{
LOS HACENDADOS Y RANCHEROS MAYAS DE YUCATÁN EN EL SIGLO XIX*
}

\author{
Laura Machuca Gallegos \\ Centro de Investigaciones y Estudios Superiores en Antropología Social
}

En febrero de 1842, el viajero John Lloyd Stephens llegó al rancho Kiwic en Yucatán y describió a su dueño de la siguiente forma:

El tal propietario era un indio puro, el primero de esta antigua pero degradada raza a quien hubiésemos visto en la posición de ser dueño y propietario de tierras: era como de cuarenta y cinco años de edad y muy respetable en su apariencia y maneras. Había heredado de sus padres aquella finca, sin saber cuánto tiempo hacía que se les hubiese transmitido, si bien estaba en la creencia de que siempre había estado en su familia. Sirvientes suyos eran los indios del rancho, y en ningún pueblo o hacienda habíamos visto hombres de mejor apariencia y mejor disciplinados [...] No es exacto que el indio sea apto solamente para los trabajos manuales, sino que es muy capaz de poseer lo que se necesita para dirigir los trabajos de otros... (2003: 324).

Stephens se sorprendió al constatar que un indio podía ser "amo", pero el cacique de Kiwic no era el primero ni el último en serlo. En Yucatán, desde la época colonial ha existido el binomio "blanco" versus indio. El primer término se ha aplicado a toda persona no maya y hace clara referencia no sólo al color de piel sino a todo un universo concebido aparte de lo indígena. La imagen de que sólo los grupos "blancos" y pudientes de la sociedad eran propietarios de haciendas y ranchos, y que los mayas no tuvieron más remedio que servir ahí debido a su pobreza, no ha dejado percibir en su justa dimensión los proyectos económicos individuales de un grupo de indígenas que, si bien es minoritario, no permaneció al margen de los sistemas económicos dominantes.

En este trabajo me ocuparé de los amos mayas, seguiré algunas de sus estrategias y reconstruiré sus lazos sociales. Para realizar lo anterior, he utilizado documentos de carácter notarial, en particular los testamentos y los intestados,

\footnotetext{
* Una versión preliminar de este trabajo fue presentada como ponencia en el VII Congreso Internacional de Mayistas, realizado en Mérida, Yucatán, del 8 al 14 de julio de 2007. El artículo forma parte del proyecto "El concepto maya de 'desarrollo' frente a los modelos socio-regionales siglos xvı al xxı”, con financiamiento del Fomix Yucatán coordinado por la Dra. Gabriela Solís, del Centro de Investigaciones y Estudios Superiores en Antropología Social (CIESAS). Agradezco los comentarios realizados a este trabajo por el Dr. Ricardo López Santillán de la Universidad Nacional Autónoma de México y el de los dictaminadores anónimos. También agradezco a Emiliano Canto Mayén, ex becario, por su ayuda en la búsqueda y trascripción de algunos testamentos.
} 
escritos en español, que prácticamente han sido la única vía para entrar en la vida de estos mayas, a quienes he identificado como tales por el patronímico. Susan Kellog y Matthew Restall (1998: 2) han escrito acerca de los testamentos que:

A través de este simple género de fuente de documento notarial, los elementos textuales se encuentran para proveer una minuciosa pintura de un individuo particular o grupo. En América Latina colonial, la mayoría de los testadores individuales eran analfabetos, pero gracias al amplio acceso a lo que llamaremos 'el alfabetismo legal', las voces de las no élites, tan seguido buscadas por el historiador social, llegan a estar disponibles.

Los testamentos, como fuente primordial para el análisis histórico, han sido utilizados por varios investigadores del área maya como el mismo Mattew Restall (1995), quien recopiló los del pueblo de Ixil; Mario Ruz (2001 y 2002), quien trabajó diversos casos de mayas guatemaltecos y yucatecos; y Paola Peniche (2007), quien analizó el parentesco y las formas de herencia entre los mayas. ${ }^{1}$

Nosotros hemos trabajado con una serie de testamentos e intestados del siglo xix que pertenecen al aún poco explorado ramo de justicia civil del Archivo General del Estado de Yucatán. Se han utilizado cuando entre los bienes se consignó una hacienda, un rancho, un sitio o un paraje, y cuando en las dos últimas situaciones contaban con ganado, colmenas, siembra de maíz o un sirviente adeudado. Mi muestra está conformada por veintidós mayas (18 hombres y cuatro mujeres, con sus maridos) que redactaron su testamento o murieron intestados entre 1830 y 1879, tres del barrio de Santiago de Mérida (Manuel Koyox, Antonio Xul y Hermenegildo Caamal), tres de Kinchil (el padre e hijo José Gertrudis y José Tzuc y Crisanto Chac), dos de Halachó (los esposos Buenaventura Cab y Dominga Choch), uno de Teya (José María Uicab), uno de Tipikal (Juan Ek), uno de Homún (José María Chim), uno de Mocochá (Clemente Chan), una de Samahil (Felipa Pech), uno de Bokobá (Pedro Chan), uno de Tecoh (Pablo Chablé), uno de Tixpehual (Laureano Puc), uno de Seyé (José María Chuc), uno de Tunkás (José María Uc), uno de Hunucmá (Bruno Ek), una de Ixil (Josefa Pech), una de Muna (Juana Cocom) y uno de Hocabá (Eustaquio Dzul) (ver cuadros y mapa al final).

\section{La hacienda en Yucatán}

Hace más de cincuenta años François Chevalier (1999) publicó su clásico libro sobre la hacienda, donde se asentaron varias de las ideas generalizadas que se tienen ahora de este sistema económico, como la autosuficiencia, las relaciones de señorío o la de propietarios absentistas. Desde hace algún tiempo ya se trabaja sobre casos regionales, que han mostrado ser cada uno modelos completamente distintos.

${ }^{1}$ También se han publicado los testamentos de Tekantó y de Ebtún (gracias a Philip Thompson y Ralphs Roys, respectivamente). 
Así, en Yucatán la hacienda nació tardíamente, hacia fines del siglo xvIII, justo cuando se vivía en varias partes de la Nueva España un proceso de impulso de la propiedad individual. Al perfilarse como el más importante sistema económico, a aquélla accedieron no sólo los estratos más favorecidos de la sociedad sino otros grupos, que hasta el momento se habían mantenido al margen, surgiendo así un sector medio rural (Van Young, 1992; García Ugarte, 1992 y Gómez Serrano, 2000). Las haciendas yucatecas de antes del porfiriato, salvo muy pocas excepciones, no pueden compararse ni con las construcciones actuales ni mucho menos con las del centro y norte de México. Eran empresas de agricultura y ganado (siendo éste y sus derivados donde se concentraba la mayor inversión junto con la deuda de criados), con construcciones modestas en tamaño e infraestructura y con altas deudas hipotecarias. Quizá un rasgo esencial de la hacienda yucateca sea precisamente sus proporciones y sus bajos avalúos. De hecho, la frontera entre rancho y hacienda para el Yucatán decimonónico resulta bastante difusa y a veces las dos propiedades suelen confundirse. ${ }^{2}$

Terry Rugeley (1996: 20) ha descrito las haciendas de los mayas como liliputianas. Hablamos de propiedades valuadas entre los 200 y los 5000 pesos, aunque una mayoría está gravada con censos e hipotecas, modelo que no difiere con el de sus otros homólogos yucatecos. Se tienen consignados algunos nombres de amos mayas por las ventas que realizaron de sus propiedades, ya sea en vida o a través de sus herederos una vez muertos los amos, aunque no se cuenta con más datos. Ese sería el caso de Antonio Pisté, dueño de Kehuelmay; Pascuala Balam, de Xhobonyá; Pedro Cab, amo de Tzutzuyil; o Antonio Cocom, de Xluch (Guiémez Pineda, 2005a: 746, 750-751; 2005b: 222-224, 228-229). ${ }^{3}$

Analicemos en las siguientes líneas las características generales de las propiedades de los amos mayas. En los cuadros 5 y 6 se puede observar que su valor, cuando se consigna, podía ir desde 40 pesos por un paraje (de Pedro Chan de Bokobá) hasta 2838 por una hacienda (de José María Chuc de Seyé). Sí se nota una gran diferencia entre los que dictaron testamento y los intestados. Sin ninguna duda alcanzaban valores más altos las propiedades de los testadores, en donde se cuentan varios caciques, aunque tampoco se trata de un modelo único, pues entre los intestados hay un ex cacique cuya propiedad sólo alcanzó los 377 pesos (José Tzuc). En ese grupo el paraje Xcacalchén de Felipa Pech alcanzó un valor de 909 pesos, seis reales.

En otro trabajo ya habíamos hecho notar (Machuca Gallegos, 2007) que en las haciendas yucatecas, antes del boom henequenero, la mayor inversión era de ganado. Este modelo se sigue aplicando al caso de los mayas analizados, pues el porcentaje va desde un $39 \%$ hasta un $94 \%$ del valor total de la propiedad. La inversión en la planta (infraestructura) o en colmenas es mínima.

\footnotetext{
${ }^{2}$ Por ejemplo, en la zona del azúcar se habla de ranchos azucareros, pero podían ser tan o más grandes que una hacienda.

${ }^{3}$ Para Pedro Cab ver "Sucesión Testamentaría de Manuel García Sosa, quien fuera vecino de Mérida”, Archivo General del Estado de Yucatán (AGEY), justicia civil, vol. 29. exp. 25, 1842.
} 
En el grupo de testadores, sin ninguna duda se encuentran mayas pudientes que poseían casa, solares, joyas y diversos muebles y utensilios; el que menos dejó, 450 pesos (Laureano Puc de Tixpehual); el más solvente resultó ser José María Chuc, de Seyé, con bienes que ascendían a 2863 pesos. De los intestados, algunos consignan propiedad de solares y casa, fluctuando las fortunas entre 244 (de Juan Ek de Tipikal) y 2853 pesos (de Clemente Chan de Mocochá).

\section{Análisis de los testamentos e intestados}

Para el análisis de los testamentos, hemos seguido el modelo de Jacques Poloni Simard (1998 y 2002), quien parte de la idea de que la búsqueda de los lazos interindividuales permite poner en evidencia los medios sociales en los cuales los actores se inscribían. Para lograrlo utiliza tres variables relacionales: los cónyuges, los albaceas y los testigos. Aunque nosotros hemos agregado también a los deudores y a los sirvientes adeudados.

La variable del cónyuge resulta importante, pues permite saber en qué medio se escogían las esposas (os) y si algunos rebasaban su ámbito étnico a través de este sacramento. En la muestra analizada (ver cuadros 4 y 7) se encuentran dos tendencias diferentes según si eran intestados o testadores. En el primer grupo, de intestados, compuesto de nueve personas, siete se casaron una vez, uno lo hizo dos y un último (José Tzuc) tres. Todos los cónyuges eran mayas. De los trece testadores, cinco contrajeron nupcias una vez, seis dos veces, y dos (Pedro Chan y José María Chuc) tres. En tres casos de segundo y tercer matrimonio pensamos que la esposa ya no era maya por el apellido: así consideramos a Juliana Baldez, Juliana Ávila y Jacinta Aguayo. Ninguna esposa aportó nada a la unión, a excepción de Jacinta Aguayo (casada con Hermenegildo Caamal), quien lo hizo con un rosario de oro y coral, una venera de coral, cinco pares de aretes y dos pares de argollas de oro (al parecer, ella también era viuda). En el caso de primeras nupcias sólo Eustaquio Dzul contribuyó con dos tablajes de tierras, la tercera parte de otro paraje, un solar y dos novillonas. Todos los demás testadores manifestaron haber llegado a su matrimonio sin bien alguno.

Vale la pena hacer una breve mención al número de hijos (cuadros 4 y 7), los cuales iban desde ninguno (el caso de Juana Cocom ) y uno que tuvo Antonio Xul, hasta los diez de José Tzuc y los once de Buenaventura Cab y su esposa Dominga Choch, siendo el número promedio de cinco. Lógicamente, con tanto hijo había que encontrar la fórmula más apropiada para que las propiedades no fueran divididas, como se verá más adelante.

Los albaceas constituían una figura muy importante, pues se encargaban de ejecutar la última voluntad del testador, de ahí que se escogieran con cuidado. Por lo general eran parientes: en primer lugar, la o el cónyuge o uno de los hijos, después un hermano o yerno. Sin embargo, los trece testadores (cuadro 4) siguieron un patrón ligeramente diferente: cuatro nombraron a sus esposas y sólo dos 
las pusieron en primer lugar; seis eligieron a sus hijos, pero únicamente cuatro encabezan la lista; tres prefirieron a sus hermanos, dos a sus nietos, otros dos a sus cuñados y uno a su suegro. En cinco casos también se designó a albaceas externos a la familia: José María Uc, de Tunkás, escogió a don Juan Isidro Pérez; Eustaquio Dzul, de Hocabá, a don Pedro Arsiquea y don Casimiro Echevarría (de hecho Arsique también sería curador de sus hijos pequeños), y José María Chuc, de Seyé, escogió a don José Dolores Rodríguez y a don José Gil Angulo. Pedro Chan, de Bokobá, a don Buenaventura Martínez; y Bruno Ek, de Hunucmá, nada menos que a Santiago Méndez, varias veces gobernador de la península. Si se observa, el "don" marca cierta preeminencia y los nombres a todas luces no son mayas. Desafortunadamente, en el estado actual de nuestras investigaciones no sabemos aún quienes eran ellos. En todo caso, quizá los testadores pensaban que la gestión y repartición de bienes sería mejor llevada a cabo por "blancos".

Simard observó respecto a la región de Cuenca que la preferencia de escoger al albacea entre la familia no era general: era mayoritaria para los indios (los caciques e indios preferían su propio mundo), media para los cholos o mestizos y muy baja para los mestizos, quienes tendían al mundo de los blancos. Los clérigos también eran muy socorridos, pero en nuestra pequeña muestra no aparecen; más bien los encontramos en los testamentos de los grupos mestizos y blancos.

Los testigos eran escogidos fuera del círculo familiar y se necesitaban al menos tres personas para validar el testamento. Sin embargo, es posible que los testigos más bien sean parte de las relaciones del notario y no del testador, por lo que resulta arriesgado sacar conclusiones de estos datos, dada la inexactitud de la fuente para medir la fuerza de los lazos. De los 45 testigos asentados (cuadro 4), de apellidos mayas únicamente había cinco. Sólo en un caso se observa que se cruza la variable de testigo con la de clientela: José Gertrudis Tzuc debía 72 pesos al presbítero Tranquilino Sánchez. Se puede notar que para la validación de los testamentos, al menos los notarios tenían una preferencia por el sector "blanco".

Otro rubro que consideramos de gran importancia es el de las deudas. No sólo resulta sobresaliente saber si los mayas analizados contraían préstamos, sino con quién, pues esto también es un indicador de los diferentes ámbitos en que se desenvolvían. Como se puede observar en el siguiente cuadro, sólo cinco consignaron tener deudas, pero en los casos de Bruno Ek y sobre todo de Josefa Pech (que se analiza más adelante) resalta tanto la cantidad como el número de sus prestamistas, lo que nos indica el enorme crédito social con el que contaban.

Sólo dos testadores parecen tener relaciones de dependencia con gente fuera de su ámbito: Pedro Chan de Bokobá debía 40 pesos a Manuel Canto de Calcalchén a cuenta de cuatro mulas que estaban por nacer. De hecho, al parecer en este pueblo Chan mantenía lazos fuertes, pues su albacea, don Buenaventura Martínez, también era de este lugar. Asimismo, Buenaventura Cab, de Halachó, tenía algunas deudas en la villa de Calkiní: debía 100 pesos a don Susano Gon- 
zález, a quien había dejado en hipoteca su paraje Chumbec; a don Nicolás García (de la misma villa), 38 pesos; y a don José Téllez, de la ciudad de Campeche, el valor de cinco mil ajos.

Cuadro 1. Deudas de los testadores

\begin{tabular}{|c|c|c|c|}
\hline Testador & Prestamistas & Procedencia & $\begin{array}{l}\text { Cantidad en pesos } \\
\text { o especie }{ }^{4}\end{array}$ \\
\hline $\begin{array}{l}\text { Pedro Chan } \\
\text { (Bokobá) }\end{array}$ & Manuel Canto & Cacalchén & 40 \\
\hline $\begin{array}{l}\text { Buenaventura Cab } \\
\text { (Halachó) }\end{array}$ & $\begin{array}{l}\text { Susano González } \\
\text { Nicolás García } \\
\text { José Tellez }\end{array}$ & $\begin{array}{l}\text { Calkiní } \\
\text { Calkiní } \\
\text { Campeche }\end{array}$ & $\begin{array}{l}100 \\
38 \\
5 \text { mil ajos }\end{array}$ \\
\hline $\begin{array}{l}\text { José Getrudis Tzuc } \\
\text { (Kinchil) }\end{array}$ & Pbro. Tranquilino Sánchez & & 72 pesos \\
\hline $\begin{array}{l}\text { Bruno Ek } \\
\text { (Tipikal) }\end{array}$ & $\begin{array}{l}\text { Juan Canto } \\
\text { Juan López } \\
\text { Pedro Chacón } \\
\text { Julian Ek } \\
\text { Juan Bautista Novelo } \\
\text { Francisco Fuentes } \\
\text { José Ángel Méndez } \\
\text { Julián Cu }\end{array}$ & $\begin{array}{l}\text { Tetiz } \\
3 \text { pesos }\end{array}$ & $\begin{array}{l}40 \text { cargas de maíz } \\
8 \text { cargas de maíz } \\
32 \text { cargas de maíz } \\
7 \text { pesos } \\
2 \text { pesos } \\
7 \text { reales } \\
10 \text { pesos, } 4 \text { reales }\end{array}$ \\
\hline $\begin{array}{l}\text { Josefa Pech } \\
\text { (Ixil) }\end{array}$ & $\begin{array}{l}\text { Doña Feliciano Aguilar } \\
\text { Lorenzo Pech (hermano) } \\
\text { Doña Isabel Zapata } \\
\text { Doña Luz Gutiérrez } \\
\text { Bonifacio Garma } \\
\text { Cunegunda Yaneb } \\
\text { Don José Inés Villamil } \\
\text { Don Juan Pío Aguilar } \\
\text { Don Pedro Capetillo } \\
\text { Doña Josefa Navarrete } \\
\text { Don Anastasio Loza }\end{array}$ & Todos de Ixil & $\begin{array}{l}200 \text { pesos } \\
125 \text { pesos de } 5 \text { lonas } \\
7 \text { pesos (cadena oro) } \\
3 \text { pesos, } 3 \text { reales } \\
2 \text { pesos } \\
4 \text { pesos } \\
3 \text { pesos, } 3 \text { reales } \\
10 \text { pesos } \\
10 \text { pesos, } 11 / 2 \text { (por joyas) } \\
5 \text { pesos } \\
31 \text { pesos, } 2 \text { reales }\end{array}$ \\
\hline
\end{tabular}

Fuente: Testamentos del Archivo General del Estado de Yucatán (AGEY).

Como se puede observar en el cuadro 2, existía un grupo de seis mayas a quienes se les debía dinero o mercancías. Cab poseía una tienda, de ahí se explica que también le debieran varias personas (entre ellas don Pablo Fuentes, don Domingo Loaeza y don Teodoro Pacheco) cantidades que van de los dos a los ocho pesos. Don José Higinio Flores le pagaría 18 pesos, cuatro reales de la deuda de un sirviente que le había transferido Cab. Aunque sólo de él se tiene la certeza que poseía tienda, es posible que los otros también hayan sido tenderos o prestamistas, lo que explicaría su "solvencia”. Igualmente llama la atención su campo de acción,

${ }^{4}$ Cabe recordar que un peso estaba compuesto por ocho reales. 
pues en algunos casos como el de Chuc o Ek, su clientela se ampliaba a otros pueblos no tan cercanos. Ek, por ejemplo, vivía en Hunucmá y tenía un deudor en Halachó; y Chuc de Seyé mantenía sus vínculos en Tixkokob (ver mapa).

Cuadro 2. Deudores de los testadores

\begin{tabular}{|c|c|c|c|}
\hline Nombre testador & Deudor & Lugar & $\begin{array}{l}\text { Cantidad pesos } \\
\text { y reales }\end{array}$ \\
\hline $\begin{array}{l}\text { José María Uc* } \\
\text { (Tunkás) }\end{array}$ & $\begin{array}{l}\text { Cantero José Tamay } \\
\text { Damaso Pech } \\
\text { Juan Pech } \\
\text { Francisco Bovadilla } \\
\text { Leonardo Couoh } \\
\text { Juan Pedro Couoh } \\
\text { Manuel Jesús Rendón } \\
\text { Juan Camal }\end{array}$ & & $\begin{array}{l}25,5 \\
2,3 \\
2 \\
2 \\
1 \\
0,7 \\
3,4 \\
3,4\end{array}$ \\
\hline $\begin{array}{l}\text { José María Chuc } \\
\text { (Seyé) }\end{array}$ & $\begin{array}{l}\text { Santiago Canul } \\
\text { Juan Canul } \\
\text { Desiderio Varguez }\end{array}$ & $\begin{array}{l}\text { Tixkokob } \\
\text { Tixkokob }\end{array}$ & $\begin{array}{l}9 \\
6 \\
8\end{array}$ \\
\hline $\begin{array}{l}\text { Eustaquio Dzul } \\
\text { (Hocabá) }\end{array}$ & & & 35 \\
\hline $\begin{array}{l}\text { Bruno Ek } \\
\text { (Hunucmá) }\end{array}$ & $\begin{array}{l}\text { Pablo Fuentes } \\
\text { Cacique Rufino Matú } \\
\text { Juan Novelo } \\
\text { Julián Ek } \\
\text { Manuel Ek } \\
\text { Albañil Mario Cahuich }\end{array}$ & $\begin{array}{l}\text { Halachó } \\
\text { Hunucmá }\end{array}$ & $\begin{array}{l}10 \\
\text { En trabajo } 5 p \\
5 \text { cargas maíz } \\
4 \text { cargas maíz } \\
3 \text { rollizos } \\
\text { Obra de su casa }\end{array}$ \\
\hline $\begin{array}{l}\text { Josefa Pech } \\
\text { (Ixil) }\end{array}$ & $\begin{array}{l}\text { Don Inocencio Velásquez } \\
\text { (yerno) }\end{array}$ & & 100 pesos \\
\hline $\begin{array}{l}\text { Buenaventura Cab } \\
\text { (Halachó) }\end{array}$ & $\begin{array}{l}\text { Don Pablo Fuentes } \\
\text { Don Domingo Loaeza } \\
\text { Don Teodoro Pacheco } \\
\text { Don José Higinio Flores }\end{array}$ & $\begin{array}{l}\text { Halachó } \\
\text { Idem } \\
\text { Idem } \\
\text { Idem }\end{array}$ & $\begin{array}{l}6 \\
8 \\
2 \\
18,4\end{array}$ \\
\hline
\end{tabular}

* Le deben otros más que constan en sus apuntes que no venían en el testamento.

Pasaré a la última variable: la de los sirvientes adeudados. Aunque se trata de una relación de dependencia se ignora en qué condiciones vivían los sirvientes en estas propiedades o qué lazos exactamente podían haber establecido con sus patrones. 
Cuadro 3. Sirvientes adeudados

\begin{tabular}{|c|c|c|}
\hline Propietarios & Sirvientes & Deudas \\
\hline $\begin{array}{l}\text { Buenaventura Cab } \\
\text { Dominga Choch }\end{array}$ & $\begin{array}{l}\text { Laureano Collí } \\
\text { Dionisio Ku } \\
\text { Pedro Ucan } \\
\text { José María Chiu } \\
\text { Leandro Euan } \\
\text { Crisanto Cu }\end{array}$ & $\begin{array}{l}30,25 \\
28,75 \\
24,50 \\
10,50 \\
24,50 \\
18,50\end{array}$ \\
\hline Buenaventura Cab & $\begin{array}{l}\text { Dionisio Ku } \\
\text { Laureano Collí }\end{array}$ & 60,1 \\
\hline Eustaquio Dzul & Mayoral & 43 \\
\hline Pedro Chan & ¿? & 75 \\
\hline José María Uc & $\begin{array}{l}\text { Antonio Yupit } \\
\text { Gregorio Vacal }\end{array}$ & $\begin{array}{l}34,6 \\
0,4\end{array}$ \\
\hline Juan Ek & Bruno Burgos & 5 \\
\hline Nicolás Uc & $\begin{array}{l}\text { Lucas Xul } \\
\text { José Can } \\
\text { Apolonio Ciau } \\
\text { Guillermo Villalobos }\end{array}$ & $\begin{array}{l}33,1 \\
26 \\
31 / 2 \\
3,4\end{array}$ \\
\hline $\begin{array}{l}\text { José Clemente } \\
\text { Chan }\end{array}$ & $\begin{array}{l}5 \text { en un solar } \\
6 \text { en su paraje } \\
\text { Mayoral }\end{array}$ & $\begin{array}{l}77,12(15 \mathrm{c} / \mathrm{u}) \\
149(25 \mathrm{c} / \mathrm{u}) \\
14\end{array}$ \\
\hline José María Chim & ¿? & 85 \\
\hline José María Chuc & $\begin{array}{l}\text { Esteban Chuc } \\
\text { Domingo Chay } \\
\text { Antonio Tec } \\
\text { - }\end{array}$ & $\begin{array}{l}10,4 \\
7,4 \\
2,4 \\
9\end{array}$ \\
\hline Felipa Pech & $\begin{array}{l}\text { José Kú } \\
\text { Fermín Ku } \\
\text { José Chan } \\
\text { Juan Crisóstomo Pech } \\
\text { Victoriano y Nicolás Can } \\
\text { Bartolomé Can } \\
\text { Cesáreo Kooh } \\
\text { Luciano Ek } \\
\text { Marcos Chan } \\
\text { Simón Catzím } \\
\text { Silvestre Dzib } \\
\text { José Ku } \\
\text { Luis Ku } \\
\text { Hipólito Ek } \\
\text { Basilio Dzib } \\
\text { Anacleto Dzib } \\
\text { Gervasio Borjes } \\
\text { María Borges } \\
\text { Pedro Salas }\end{array}$ & $\begin{array}{l}1,7 \\
2,1 \\
4 \\
1 \\
2,6 \\
1 \\
2,5 \\
3 \\
3,2 \\
1,7 \\
2,5 \\
8 \\
2,2 \\
1,4 \\
61 / 2 \\
1,1 \\
1,4 \\
6 \\
6\end{array}$ \\
\hline
\end{tabular}




\begin{tabular}{|l|l|l|}
\hline Propietarios & Sirvientes & Deudas \\
\hline & Esteban Gómez & 3 \\
& Patricio Borjes & 3,6 \\
& Feliciano Franco & 1,4 \\
& George Chacón & 1,1 \\
& Benito Dzib & 1,5 \\
& Bernardo Pool & $1 / 2$ \\
& Isidro Ek & $51 / 2$ \\
& Feliciano Chi & 3,2 \\
& Julio Dzib & 3,6 \\
& Higinio Can & 3,3 \\
& Gregorio Can & 1,5 \\
& Gaspar Koh & $1 / 2$ \\
& Juan Pol & 3,1 \\
& Mateo Pech & 2,3 \\
& Santiago Ek & $1 / 2$ \\
& José María & 1,4 \\
& Salazar & 3 \\
\hline \multirow{7}{*}{ Josefa Pech } & 1 criado de Paiché & $41 / 2$ \\
& 8criados de San José & $168.2 \frac{1}{2}$ \\
\hline
\end{tabular}

Fuente: Testamentos del AGEY.

Si se observa el cuadro tres se puede apreciar que varios amos mayas tenían entre uno y cuatro sirvientes. Algunos debían cantidades mínimas como un peso, pero otros sorprendentemente podían alcanzar altas sumas de hasta 85 pesos. Según Rugeley (1996: 20), particularmente en las propiedades de los caciques las relaciones amo-sirviente se vivían de manera diferente, pues había una preocupación por que la producción se repartiera equitativamente, sacrificando un poco las ganancias en aras del apoyo político. En ese sentido, se observa que los caciques contaban con un número muy reducido, o ninguno, de sirvientes adeudados. Al contrario, quienes no ostentaban dicho título tenían más sirvientes con el mayor número de deudas. En todo caso, a diferencia de los amos blancos, ninguno en sus testamentos se acordó de sus sirvientes de hacienda antes de morir. En realidad sólo Antonio Xul pensó en la criada de su casa. Sin duda, esta información rompe con un esquema tradicional, pues el maya no cacique también podía dominar.

Igualmente llaman la atención los 35 criados de Felipa Pech, vecina de Samahil. Ella era viuda de Vicente Pech y murió en octubre de 1847. Entonces sus hijos hicieron el inventario de "los pocos bienes" que quedaron de su madre. ${ }^{5}$ Resultó que su rancho Xcacalchén estaba valuado en 909 pesos (220 pesos la planta, 286 la milpa, 46 de colmenas y 357 de ganado) y que los 35 criados debían 80 pesos, en realidad una vasta mano de obra pero adeudada con cantidades mínimas. Sus

5 "Diligencias practicadas con motivo del intestado de la finada Felipa Pech, vecina que fuera de Samahil”, AGEY, justicia civil, vol. 44, exp. 21, 1847-1848. 
bienes totales ascendieron a 1099 pesos y después de las bajas a cada uno de los cinco hijos se le entregaron 196 pesos, entre ellos María Petrona Pech, quien dictó testamento años después en 1867 y por eso pudimos seguir un poco más la pista a la familia. El rancho no se vendió, más bien fue compartido entre los hermanos, siguiendo una estrategia que ya mencionamos más arriba.

Gracias a la herencia de su madre, Petrona pudo aportar a su matrimonio con Paulino Caamal 16 cabezas de ganado vacuno, tres yeguas, un capón, 50 corchos de abejas, 30 cargas de maíz, 30 mecates de milpa rosa y su parte del rancho Cacalchén, aunque ellos ya no consignaron sirvientes adeudados. ${ }^{6}$ Con los años, ella y su esposo aumentaron sus bienes. De esta forma adquirieron además un solar, cuatro vacas, cuatro mulas, 31 corchos de abeja, 60 mecates de milpa roza y 40 de milpa caña, tres potrancas, dos rosarios engarzados de oro y una cadena. Sus bienes sumaron 349 pesos. $^{7}$ Sin embargo, el matrimonio no logró aumentar más que someramente los bienes heredados.

Como hemos visto, los lazos establecidos por los mayas propietarios eran de diferente naturaleza (familiar, de amistad, de dependencia), duración y geografía. Se privilegia el ámbito familiar e indígena, aunque no quiere decir que no haya apertura al mundo de los "blancos". El nivel de este acercamiento depende de cada uno, siendo los más proclives aquellos dedicados a actividades extras a la de labrador, como tendero, o en el caso de quienes vivían en el suburbio de Santiago de la ciudad de Mérida, individuos más bien urbanos. El hecho de ser maya no implicaba relaciones igualitarias con sus pares; sin ninguna duda la tierra y la propiedad otorgaban un estatus y los amos mayas podían gozar de la prerrogativa (a semejanza de los "blancos") de tener sirvientes adeudados.

\section{Los caciques y sus familias}

Durante el siglo xix, el cargo de cacique, que se encontraba en el primer nivel del cabildo indígena (equivalente al gobernador en el centro de México), se obtenía a través de elecciones, con una terna que era propuesta al gobierno por el subdelegado y el cura. Entre las condiciones que un cacique debía cubrir para ocupar tal puesto estaba la capacidad en el cobro de obvenciones, pero también la calidad moral y la solvencia económica (Giiémez, 2005b: 147). Dada su posición, los caciques tuvieron la capacidad de obtener más tierras. Pasemos a ver los casos concretos.

Santiago Chablé, cacique del pueblo de Tecoh, compró en 1827 la hacienda Kukulá al coronel Felipe de la Cámara, en mil pesos por la planta, pero con gra-

\footnotetext{
6 “Testamentaría de María Petrona Pech, vecina que fue del rancho 'Cacalchén' jurisdicción del pueblo de Samahil”, AGEY, justicia civil, vol. 134, exp. 27, 1867-1868.

7 “Intestado de María Dionisia Cetz vecina que fue del pueblo de Bokobá”, AGEY, justicia civil, vol. 150 , exp. 33, 1869-1875.
} 
vamen de 1116 pesos. ${ }^{8}$ En los 15 años que tuvo la hacienda ésta apenas creció y en 1842 su viuda Petrona Ceh la vendió a Juan Bautista Ávila en 1200 pesos, pero sólo recibió 200 en razón del gravamen. En realidad, de Santiago se sabe poco, pero de su padre Pablo Chablé se puede decir más. ${ }^{9}$

Pablo se casó en primeras nupcias con Dionisia Puch, de cuya unión tuvieron a Santiago, Casimiro, Juana, Lorenza y Juan. Ninguna de las partes contribuyó con bien alguno a la unión, pero lograron hacerse de la hacienda Catzimechén en Homún. Cuando Dionisia murió, se repartió la mitad entre sus hijos. Pablo contrajo nuevo matrimonio con María Ceh y su aportación consistió en la mitad de Catzimechen, siete vacas, tres yeguas, tres mulas y cien colmenas. Quizá María y la esposa de Santiago, Petrona Ceh, fueran parientas. Pablo y María además adquirieron una casa, dos quintas (un solar con casa de paja), tres solares (de los cuales uno estaba sembrado de henequén) y un burro. Sólo tuvo un hijo con María, Laureano.

A pesar de que Pablo tuvo seis hijos, se nota la preocupación por que su hijo mayor quedara a la cabeza de la familia y por favorecerlo con una buena parte del patrimonio familiar, por considerar "su buen servicio y compañía que siempre me ha hecho ayudándome personalmente en los trabajos que he emprendido en mis agencias". Para ello, se valió del sistema español que permitía beneficiar a uno de los herederos con el tercio y quinto de los bienes. Así, Santiago se quedó con una de las quintas partes y un retazo de terreno que le había donado a Pablo su padrino don Manuel Navarrete. Desafortunadamente, el expediente no incluye las diligencias testamentarias, así que se desconoce el monto de sus bienes y la forma en que se repartieron. Si se observa el nombre del padrino y su apelativo (don) podemos darnos cuenta de que el padre de Pablo Chablé procuró para su hijo un protector "blanco" quien, por cierto, no lo desamparó al darle de regalo un terreno.

Otro cacique dueño de hacienda fue Francisco Uc, vecino de Santiago. Cabe mencionar que de todos los barrios de la ciudad, el de Santiago gozaba de especial estimación, era sede de un rico curato con una población mayoritaria de indios. Sus caciques se desenvolvían con especial facilidad entre el mundo maya y el "blanco".

En 1837, Francisco Uc compró la hacienda Tecoh en Izamal a María Josefa Escudero, distinguida dama de la élite local, en la suma de 4371 pesos y gravamen de 3 mil (Giiémez, 2005b: 228). Eligio Ancona (1978, IV: 40-45) cuenta de Uc que aparte de rico era muy querido por la gente "más visible" de Mérida. Cuando estalló la guerra de castas, se murmuró que él estaba implicado con otros caciques en una conspiración para asesinar blancos la noche del 15 de agosto de 1847 .

\footnotetext{
8 “Traspaso de la hacienda Kukulá, hecho al cacique del pueblo de Tecoh c. Santiago Chablé, con reconocimiento de gravámenes a favor de fondos religiosos", Archivo General de la Nación, Bienes Nacionales, vol. 13. exp. 30, 1827.

9 “Testamentaría de Pablo Chablé de Tecoh”, AgeY, justicia civil, vol. 36, exp. 13, 1844-1845.
} 
Debido al pavor que se apoderó de la población blanca, se inició una persecución contra todo indio considerado sospechoso. Uc fue entonces encarcelado; quizá sus relaciones y su dinero lo hubieran salvado pero, según Ancona, la gente del pueblo presionó muy fuerte para no dejarlo salir libre y el 22 de agosto fue ejecutado. Contamos con otros datos de Uc y su entorno gracias al testamento de su hijo adoptivo Antonio Xul, quien menciona haber recibido de Uc la hacienda San José Chenchomac y setenta cabezas de ganado.

Antonio Xul contrajo primer matrimonio con Agustina Kauil, con la cual sólo tuvo por hijo a José Rafael. En segundas nupcias se unió con Bárbara Koyoc, con quien tuvo seis vástagos. Ella era hija del cacique de Santiago, Manuel Koyoc. De hecho, éste último estaba casado con María Teodora Kauil, lo que me hace pensar que quizá Agustina y María Teodora eran hermanas o primas. La hacienda Chenchomac estaba valuada en 1668 pesos, de los cuales 800 pesos correspondían a la planta (infraestructura) y 750 al ganado. Cuando Xul murió sus bienes totales sin deudas ascendían a 1852 pesos. En el cuadro 5 se puede observar que Xul y su suegro Koyoc (con 1983 pesos) fueron quienes al morir dejaron las mayores fortunas. ${ }^{10}$ De hecho, Xul murió en diciembre de 1858 y el segundo por agosto o septiembre del siguiente año.

El cacique de Santiago, Manuel Koyoc, asentó en su testamento, redactado en 1858, que cuando él se casó ni él ni su esposa María Teodora Kauil aportaron nada al matrimonio y declaró como sus bienes una casa de mampostería con un costo de 600 pesos, cifra sumamente alta, pues las casas por lo regular costaban entre 50 y 300 pesos; además consignó un sitio llamado San Lorenzo con ganado que valía 739 pesos, entre solares, imágenes de santos y joyas, lo cual fue dividido entre su esposa y sus cinco herederos. ${ }^{11}$

Por último, mencionaré al cacique de Kinchil, José Tzuc, quien se casó tres veces y al morir en 1865 era viudo con 9 hijos. José era dueño del sitio Santa Rosa, cuyo valor era de 377 pesos (siendo 355 de ganado). ${ }^{12}$ Pocos años después, nos enteramos que su hijo Gertrudis Tzuc se hizo responsable de Santa Rosa, que aumentó su valor a 413 pesos, donde había introducido henequén y "he ejercido la profesión de labrador con cuyo ejercicio y el patrimonio que hube de mis padres he formado el capital de que soy propietario". Además poseía el paraje Ticopo, un tablaje de milpa, una casa con techo de guano y un solar, todo con un valor de 618 pesos. Dado que en su testamento Gertrudis no hace referencia a la manera en que adquirió Santa Rosa, cabe pensar que decidió pagar a cada uno de sus hermanos su parte correspondiente, aunque desconozco si alguno de ellos siguió viviendo en el "paraje". ${ }^{13}$

10 “Testamentaría de Antonio Xul”, AGEY, justicia civil, vol. 84, exp. 14, 1859-1872.

11 "Testamentaria del cacique del suburbio de Santiago Manuel Koyoc", AGEY, justicia civil, vol. 80, exp. 16, 1858-1862.

12 "Intestado de José Tzuc, ex cacique del pueblo de Kinchil", AgeY, justicia civil, vol. 117, exp. $5,1865$.

13 “Testamentaría de José Gertrudis Tzuc”, justicia civil, vol. 178, exp. 8. 1872. 


\section{Estrategias de herencia para conservar las propiedades}

Según Rugeley (1996: 21), a diferencia de la población española que encontraba varias vías para que sus bienes no fueran divididos, al propietario maya no le quedaba más remedio que favorecer a sus numerosos herederos, quienes tenían la opción de vender o conservar en común la propiedad, aunque en realidad también existían otras alternativas.

En este punto vale la pena hacer un paréntesis. Paola Peniche (2007: 265) en su estudio sobre el parentesco identificó dos formas colectivas de testar: la primera consistía en otorgar un conjunto de bienes a un grupo de individuos; la segunda, en apariencia favorecía a un solo heredero, como el primogénito, pero en realidad relacionaba toda una red de parentesco, por ejemplo en el caso de Pablo y Santiago Chablé antes mencionado. Es una herencia conjunta que tenía como fin evitar el fraccionamiento en el caso de solares o montes. Se trata del ch'ibal, que Mathew Restall (1997: 17) describió como un tipo de familia extendida con el mismo patronímico, donde al parecer sus miembros compartían intereses comunes, entre ellos la tierra donde no sólo vivían sino cultivaban sus milpas, criaban ganado y colmenas; además procuraban uniones matrimoniales que los afianzaran en su posición. Aunque el sistema entró en crisis a fines del siglo xvIII (Bracamonte y Sosa, 2003: 90-91 y cap. 3), los ejemplos encontrados para el xix muestran que se siguió utilizando como estrategia para la conservación de los bienes.

En el caso de Tzuc se observa cómo uno de los hijos paga su parte a sus hermanos para mantener la propiedad. ${ }^{14} \mathrm{Al}$ parecer esta práctica era bastante común. De los casos analizados, también el hijo de Laureano Puc, Crisóstomo, se adjudicó la planta del rancho Santa Cruz y pagó su parte a los hermanos. Lo mismo sucedió con Gregorio, hijo de Eustaquio Dzul, quien se quedó con el paraje Tzela y pagó su parte a los otros herederos. José María Chuc dejó su hacienda Xtihil a su hijo Facundo, con la condición de que permitiera que sus hermanos y sobrinos pudieran vivir ahí, tener sus animales y labrar en común. María Tomasa Tun, viuda de José Uicab, participó en el remate de bienes de su esposo y prefirió pagar una cantidad superior a los avalúos con tal de quedarse ella con el paraje Dzonot.

[...] declaro por bienes esta hacienda que habito titulada Xhitil y es mi voluntad dejársela a mi hijo Facundo, por la cantidad de doscientos pesos con la precisa condición: de que todos sus hermanos y sobrinos y ascendientes míos, tienen derecho de vivir en ella con sus animales y en ningún tiempo pueda evitarles ni prohibirles de que entren en el corral así como de labrar en mancomún su corto terreno sin estipendio alguno siempre que vivan y se mantengan en esta finca, sea para que conste. ${ }^{15}$

14 “Testamentaría de José Gertrudis Tzuc”, AGEY, justicia civil, vol. 178, exp. 8, 1872.

15 “Testamentaría de José María Chuc”, vol. 147, exp. 34. 1869-1870. 


\section{Las mujeres}

Resulta común que las parejas llegaran sin bienes al matrimonio y durante éste se hicieran de un rancho o de una hacienda. La muerte del esposo traía como consecuencia que las mujeres se volvieran propietarias por un tiempo. Analizaremos a continuación los casos de Josefa Pech, Juana Cocom y Domiga Choch (el de Felipa Pech ya lo comentamos antes).

Al parecer Josefa Pech era integrante de la nobleza indígena de Ixil y su marido Nicolás Figueroa parte de los indios hidalgos del mismo pueblo (Peniche, 2007: 177). Josefa redactó testamento pero en él no hace referencia a sus antecedentes familiares, por lo que nos resulta imposible situarla en su contexto familiar. Su marido murió en 1834 y dejó a Josefa con cinco hijos. Tenía una casa y varios solares valuados en 1040 pesos, la hacienda San José en 1623, incluidos diez sirvientes adeudados en 96 pesos, un rancho de pesquería que valía 633 pesos y un potrero en la playa de 428 . Además de 213 pesos que le debían algunas personas y 86 que tenía en efectivo (ver cuadros 1 y 2). Sus bienes totales ascendían a 5052 pesos. A la viuda le tocaron 2186 pesos e igual cantidad a sus hijos. ${ }^{16}$

Trece años después, en 1847, Josefa Pech dictó su testamento, aunque sus bienes disminuyeron mientras ella los administró: ${ }^{17}$ su casa se encontraba en la plaza principal de Ixil y la hacienda ahora estaba valuada en 744 pesos; sin embargo, había poblado un sitio de ganado, poseía tres canoas y dos cayucos en su rancho de pesquería, ocho solares y colmenas. Su yerno don Inocencio Velásquez le adeudaba 100 pesos. Al contrario, ella debía 151 pesos a sus tres hijos que le sobrevivían, 200 pesos en que había hipotecado su casa a doña Feliciana Aguilar, 96 pesos a su hermano Lorenzo y cantidades que van de dos a 31 pesos a diversas personas. A doña Isabel Zapata y a don Pedro Capetillo les había dejado en prenda algunas de sus joyas. Al morir sus bienes ascendieron a 1668 pesos. De Josefa Pech sobresale el hecho de que haya mantenido sola su casa y su hacienda durante tantos años; también cabe señalar que sus lazos ya no se inclinan hacia el mundo indígena. Salvo una sola mención que hace a un hermano, todas sus relaciones se dirigían al mundo "blanco"; incluso logró que una de sus hijas se casara ahí.

El caso de Juana Cocom y Pedro Barbosa resulta muy interesante, pues es el ejemplo de la movilidad social ascendente gracias a la hacienda y de una caída por las leyes de herencia. ${ }^{18}$ Tanto Juana como su esposo Pedro Barbosa eran luneros en la hacienda Chacsiniché "sin que uno ni otro contasen con más bienes que su industria, economía y trabajo"; después de grandes esfuerzos adquirieron (sin

\footnotetext{
16 "Sucesión intestada de Nicolás Figueroa quien fuera vecino del pueblo de Ixil", AGEY, justicia civil, vol. 19, exp. 4, 1834-1835.

17 “Testamentaría de doña Josefa Pech, vecina del pueblo de Ixil”, AGEY, justicia civil, vol. 43, exp. 3, 1847.

18 "Intestado de Juana Cocom vecina de la hacienda Chacsiniché", AGEY, justicia civil, vol. 61, exp. 5. 1854-1867.
} 
que sepamos cómo) la hacienda Xlabosubin. Cuando Juana murió en 1848 contaba con 200 reses, 12 caballos, 700 corchos de abejas, 15 cochinos, 12 mulas de arría y cinco luneros, además de dos casas de piedra y nueve solares en Muna. Según el marido, Juana dictó testamento y trató de hacer valer un documento dictado por ella en presencia de algunos testigos, pero unos sobrinos aprovecharon la situación para pedir que ellos también fueran incluidos en el reparto.

Pedro Barbosa hizo todo lo posible porque la propiedad no se escindiera, pues finalmente él y su esposa habían batallado para obtenerla y gracias a eso disfrutaban de cierto estatus en Muna; pero después de varios años de pugna, el juez decidió que los bienes debían ser compartidos entre las dos partes. Un tercero compró la hacienda, pero el reparto no se realizó hasta 1862 ya que Barbosa había muerto.

Por último, quisiera hacer referencia al caso de Dominga Choch y su esposo Buenaventura Cab, vecinos de Halachó. Dominga Choch murió intestada en septiembre de 1869; un año después el viudo Cab decidió que los bienes se repartieran entre él y sus 10 hijos, pues se volvería a casar. Por tal motivo nos enteramos que no aportaron nada al matrimonio y que todo su haber lo adquirieron durante éste, entre los que se encontraban una casa de cal y canto valuada en 500 pesos, 15 solares y tres parajes: Chumbec, que valía 850 pesos; Kampepem, 140; y Petac, 146. El primero consagrado a ganado, el segundo a colmenas y el tercero a la milpa. Además tenía seis sirvientes adeudados con 134 pesos. De los 1656 pesos a que ascendieron los bienes, le correspondían 788 pesos a Cab, quien se quedó con los bienes raíces, dejando a los hijos los solares y el paraje Kampepen a una de ellos. ${ }^{19}$ Cab no pudo disfrutar mucho tiempo, pues en 1874 dictó su testamento debido "a una enfermedad violenta”. Con su nueva esposa, Juliana Ávila, tuvo un hijo, pero se cuidó de especificar que a ella sólo le legaría un solar con casa y pozo; de lo contrario hubiera recibido la mitad de sus bienes y sus 11 hijos quedarían desprotegidos. Chumbec demeritó, pues su valor bajó a 638 pesos. Por alguna razón Kampepen regresó a sus manos, pero se encontraba yermo (el cual adquirió su hija Dominga en 50 pesos); tal vez vendió Petac, pero se había hecho de una tienda. Al final sólo restaron 953 pesos de la fortuna y cada uno de la numerosa progenie recibió 40 pesos.

\section{Conclusiones}

Los mayas analizados, sin lugar a duda, ocupan una posición privilegiada, unos por el simple hecho de haber tenido la capacidad de redactar un testamento, otros porque tenían algunos bienes que sus herederos juzgaron dignos de reclamar ante un juzgado (los intestados). Este puñado de personas representa un modelo atípico dentro de esa idea generalizada de que los mayas eran pobres.

19 “Intestado de Dominga Choch”, AGEY, justicia civil, vol. 160, exp. 9. 1870-1873. 
Aunque minoría, lograron romper, de cierta forma, con el "esquema" que les imponía su estatus étnico. Ninguno era menesteroso; al contrario, poseían parajes, haciendas o ranchos, solares, casas, joyas y muebles. Sus fortunas iban desde los 244 hasta los 2863 pesos, siendo comparables o superiores a la de varios "blancos". Se debe tomar en cuenta que un lunero en una hacienda apenas ganaba unos 45 pesos al año. En sus pueblos, sin duda, eran personajes respetados (algunos con cierta influencia), tanto por los mayas como por la población blanca.

Al mismo tiempo, se descubre entre estos mayas personajes activos, capaces de establecer relaciones horizontales y verticales, de naturaleza distinta según conviniera a sus intereses, moviéndose en diferentes ámbitos, cada uno desplegando diferentes estrategias para vivir mejor. Aunque en la mayoría de los casos hay una tendencia hacia el mundo blanco, del cual no podían prescindir si querían tener éxito en sus empresas, se puede observar que se le da preeminencia al ámbito familiar (tanto cuando se escogían albaceas como en el destino de las herencias).

Los caciques fueron los más privilegiados; en general poseían más recursos y preferían la fidelidad de su gente a tenerla como sirviente adeudado. Otros casos han mostrado que varios mayas en sus pueblos sin ser caciques gozaban de un nivel económico similar a la de un "blanco" promedio. Pero no sólo los hombres figuran en nuestra historia: también aparecen algunas mujeres, quienes por las circunstancias tuvieron que hacerse cargo de los negocios. Son casos excepcionales, pero que permiten acercarse a una realidad diferente a la que imaginábamos y rompe con ideas estereotipadas.

Indiscutiblemente la propiedad de la tierra proveía un estatus económico a los mayas, de ahí que varios se preocuparan por obtenerla. Pero no bastaba con tenerla ahí, improductiva: era necesario entrar a la dinámica del sistema económico imperante. La hacienda, sin lugar a dudas, se convirtió en la principal actividad económica del Yucatán decimonónico y los mayas no fueron indiferentes a tal desarrollo. Sólo una parte de la tierra se consagró a cultivar, pues la cría de ganado predominó sobre el espacio. Algunos incluso tuvieron mano de obra endeudada.

Se trata de los trozos de vida de varios indios, que estuvieron sepultados muchos años bajo el peso de los papeles. Sin ninguna duda el archivo guarda más casos como los antes referidos. Resulta labor del historiador desempolvarlos y darlos a conocer. 


\begin{tabular}{|c|c|c|c|c|c|c|c|c|}
\hline 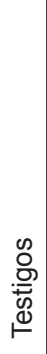 & 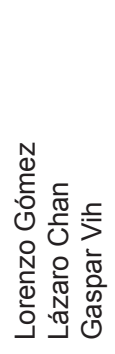 & 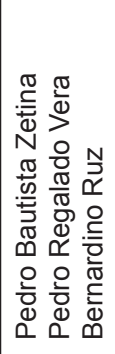 & 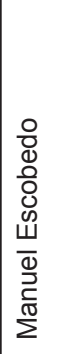 & 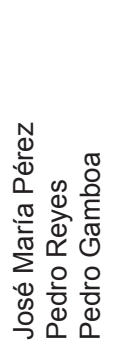 & 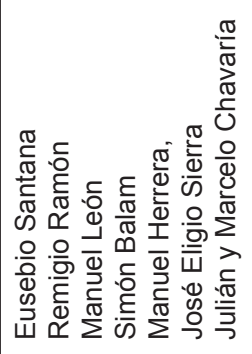 & 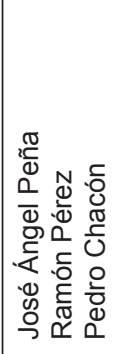 & 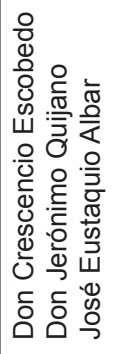 & 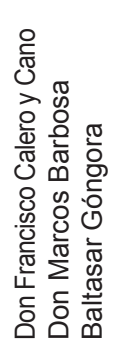 \\
\hline $\begin{array}{l}\mathbb{D} \\
\mathbb{8} \\
\mathbb{J} \\
\mathbb{N} \\
\stackrel{0}{\mathbb{4}}\end{array}$ & 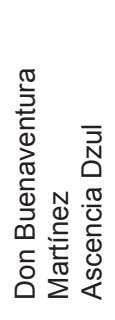 & 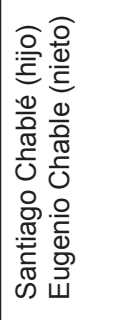 & 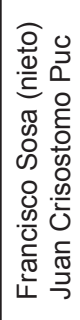 & 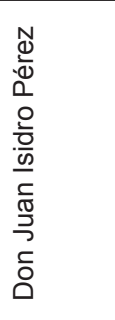 & 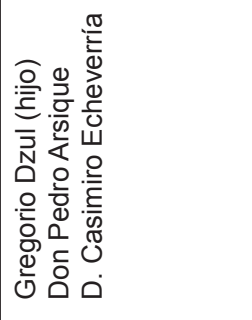 & 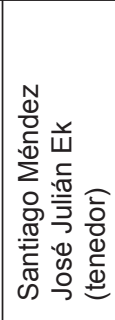 & 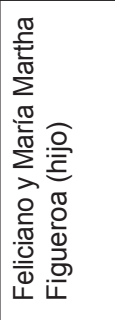 & 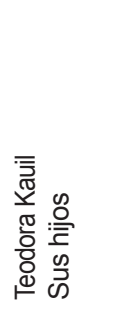 \\
\hline 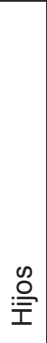 & 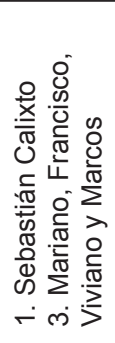 & 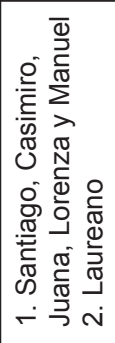 & 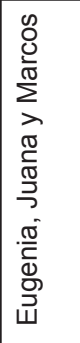 & 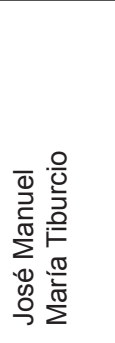 & 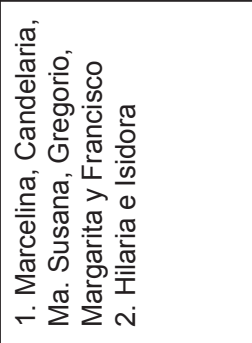 & 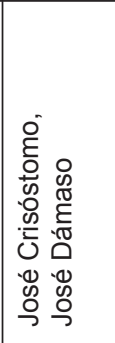 & 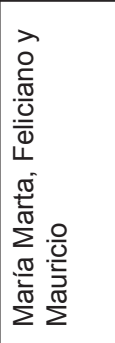 & 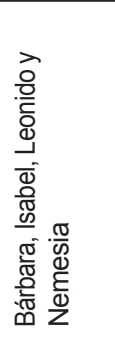 \\
\hline $\begin{array}{c}\stackrel{0}{\infty} \\
\mathscr{D} \\
0 \\
\stackrel{0}{D} \\
w\end{array}$ & 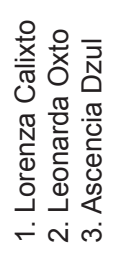 & 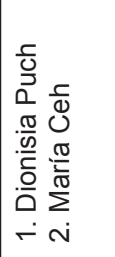 & 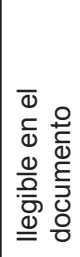 & 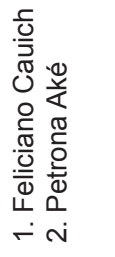 & 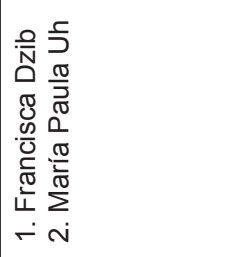 & 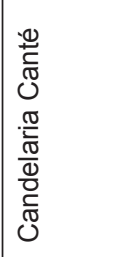 & 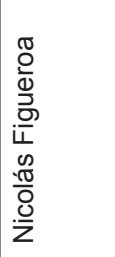 & 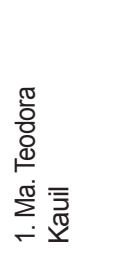 \\
\hline 爱 & $\begin{array}{l}\stackrel{ల}{0} \\
\stackrel{\infty}{\leftarrow}\end{array}$ & $\begin{array}{l}\underset{\infty}{\infty} \\
\infty\end{array}$ & $\begin{array}{l}\infty \\
\infty \\
\infty \\
\infty\end{array}$ & $\begin{array}{l}\underset{\infty}{\infty} \\
\infty\end{array}$ & $\begin{array}{l}\infty \\
\infty \\
\infty \\
\infty\end{array}$ & $\underset{\substack{\sigma \\
\infty}}{-}$ & $\begin{array}{l}0 \\
\stackrel{0}{ } \\
\infty\end{array}$ & $\begin{array}{l}\infty \\
\stackrel{\infty}{\infty} \\
\stackrel{\infty}{\infty}\end{array}$ \\
\hline \multirow[t]{2}{*}{ 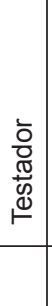 } & 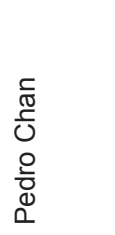 & $\begin{array}{l}\frac{0}{0} \\
\frac{0}{0} \\
\frac{0}{0} \\
\frac{0}{0} \\
\frac{\pi}{\pi} \\
0\end{array}$ & 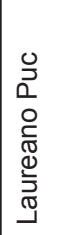 & 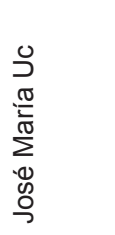 & 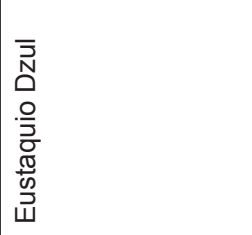 & 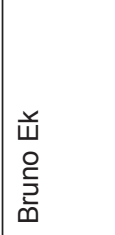 & 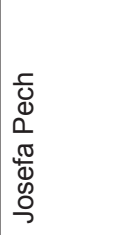 & 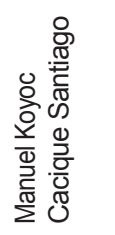 \\
\hline & - & $\sim$ & m & $\nabla$ & م & 0 & $\wedge$ & $\infty$ \\
\hline
\end{tabular}




\begin{tabular}{|c|c|c|c|c|c|}
\hline 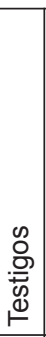 & 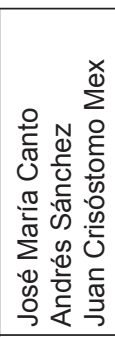 & 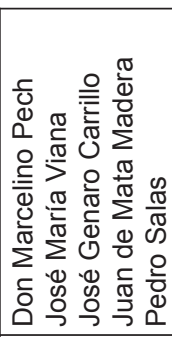 & 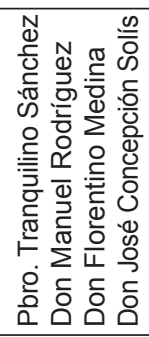 & 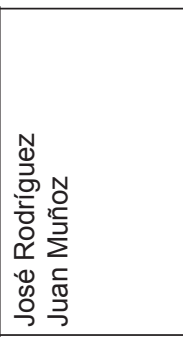 & 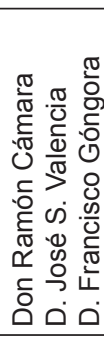 \\
\hline 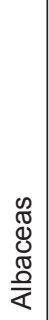 & 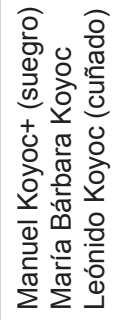 & 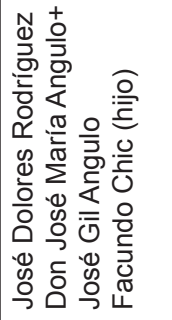 & 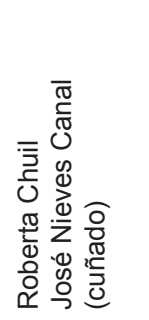 & 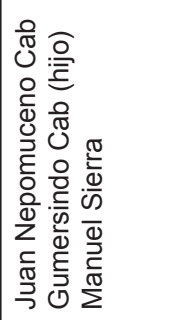 & 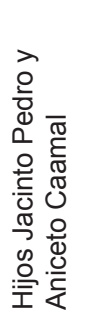 \\
\hline 哭 & 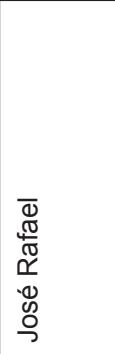 & 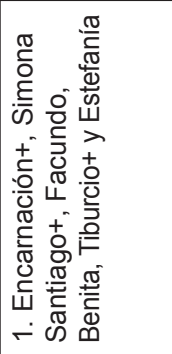 & 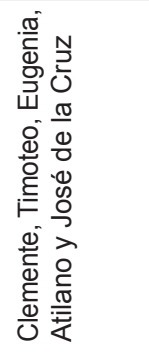 & 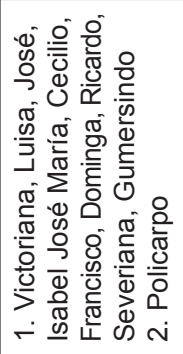 & 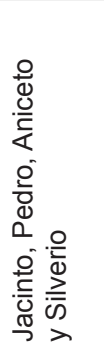 \\
\hline $\begin{array}{l}\text { D } \\
\mathbb{D} \\
0 \\
00 \\
\tilde{D} \\
w\end{array}$ & 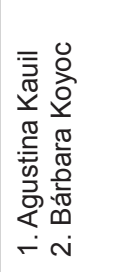 & 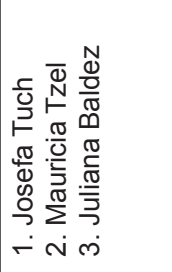 & 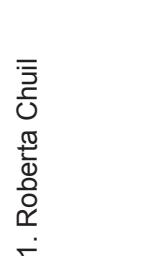 & 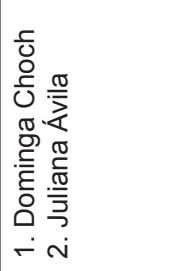 & 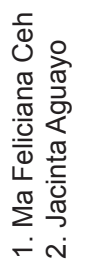 \\
\hline 寒 & $\begin{array}{l}\infty \\
\infty \\
\infty \\
\infty\end{array}$ & 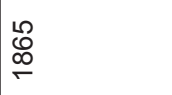 & 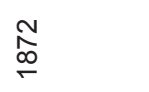 & 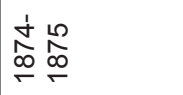 & $\begin{array}{l}\text { D } \\
\infty \\
-\end{array}$ \\
\hline \multirow[t]{2}{*}{ 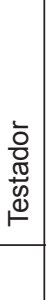 } & 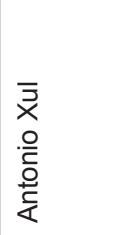 & 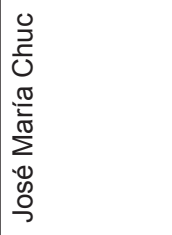 & 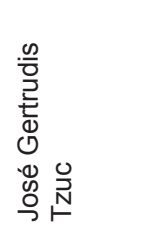 & 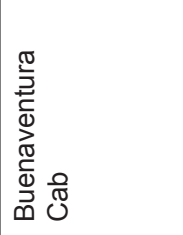 & 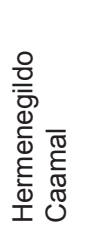 \\
\hline & $\infty$ & 음 & $\mp$ & $\stackrel{ }{\longleftarrow}$ & $\stackrel{m}{\sim}$ \\
\hline
\end{tabular}




\begin{tabular}{|c|c|c|c|c|c|c|c|c|c|c|c|c|}
\hline 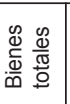 & $\stackrel{\bar{\infty}}{\circ}$ & ' & $\hat{8}$ & 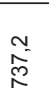 & 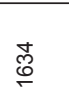 & $\begin{array}{l}\stackrel{N}{\widehat{D}} \\
\stackrel{8}{\infty}\end{array}$ & & 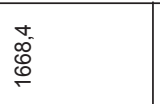 & $\begin{array}{l}\stackrel{\infty}{c} \\
\infty \\
\stackrel{\infty}{\infty} \\
\stackrel{\infty}{+}\end{array}$ & 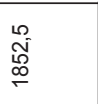 & @્心 & $\begin{array}{l}\hat{m} \\
\infty \\
\frac{0}{6}\end{array}$ \\
\hline 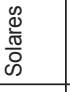 & ㅇ & & & & $\stackrel{9}{-}$ & & & 品艼 & ণั & & & g \\
\hline 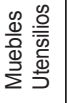 & ָ̃ & & & & $\stackrel{m}{\tilde{N}}$ & & & & $\stackrel{m}{m}$ & $\stackrel{\stackrel{ \pm}{+}}{\leftarrow}$ & & $\begin{array}{l}\tilde{\mathscr{C}} \\
=\end{array}$ \\
\hline 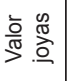 & $\ddot{\sigma}$ & & & & $\frac{N}{6}$ & & & & 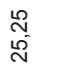 & & & $\infty$ \\
\hline 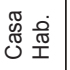 & 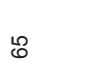 & & $\stackrel{2}{\circ}$ & & ட & ठ্ল & & $\stackrel{\circ}{\stackrel{\circ}{+}}$ & 8 & 움 & & ஜ \\
\hline $\begin{array}{l}\frac{\pi}{0} \\
\frac{\pi}{0} \\
\frac{0}{0} \\
\frac{0}{0} \\
0 \\
0\end{array}$ & $\stackrel{R}{\wedge}$ & & $\stackrel{\imath}{=}$ & $\begin{array}{l}0 \\
\dot{m}\end{array}$ & $\bar{m}$ & ? & & & & & & \\
\hline $\begin{array}{l}.0 \\
. \frac{\pi}{0} \\
\frac{0}{<} \\
\end{array}$ & 官 & $\times$ & q & $\begin{array}{l}\stackrel{L}{\infty} \\
\stackrel{p}{\longrightarrow}\end{array}$ & 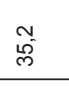 & $\stackrel{N}{\tilde{N}}$ & $\times$ & 占 & & $\frac{0}{m}$ & ळ & $\stackrel{\stackrel{\circ}{\circ}}{\rightleftharpoons}$ \\
\hline 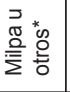 & & $\times$ & & & & $\overline{0}$ & $\times$ & & & พ & & $\infty$ \\
\hline 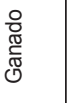 & $\stackrel{m}{\stackrel{N}{N}}$ & $\times$ & $\stackrel{\infty}{\sim}$ & \& & 志 & 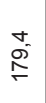 & & $\stackrel{L}{\circ}$ 寺 & 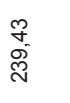 & $\frac{10}{\frac{1}{5}}$ & 孞 & 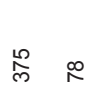 \\
\hline $\begin{array}{l}\frac{\pi}{0} \\
\frac{\pi}{0} \\
\frac{\pi}{0}\end{array}$ & 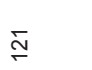 & & 8 & & প্ণ & 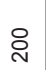 & চ্ల & 용ㅇㅁ & 吕 & ঃ & 号 & 요 \\
\hline 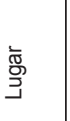 & 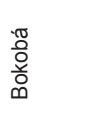 & 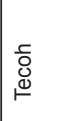 & 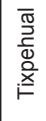 & 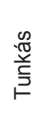 & & 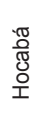 & 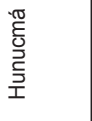 & $\overline{\bar{x}}$ & 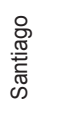 & 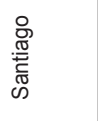 & 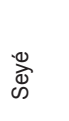 & 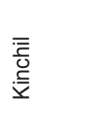 \\
\hline 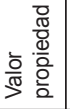 & $\underset{f}{\stackrel{f}{+}}$ & & $\stackrel{\infty}{\infty}$ & & $\stackrel{\infty}{\circ}$ & $\stackrel{\infty}{q}$ & & 娧寺 & 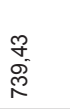 & \begin{tabular}{l}
10 \\
00 \\
$\emptyset$ \\
\hdashline
\end{tabular} & $\stackrel{\infty}{\infty} \underset{\sim}{\sim}$ & 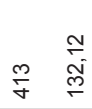 \\
\hline $\begin{array}{l}\frac{\pi}{0} \\
\frac{\pi}{0} \\
\frac{0}{0} \\
\frac{0}{2}\end{array}$ & 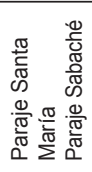 & 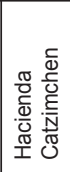 & 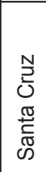 & 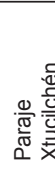 & 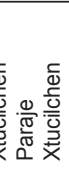 & $\begin{array}{l}\frac{\pi}{0} \\
\stackrel{N}{N} \\
\frac{0}{\pi} \\
\frac{\pi}{\pi} \\
0\end{array}$ & 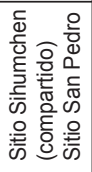 & 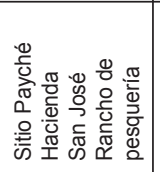 & 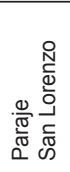 & 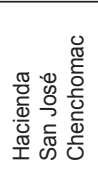 & 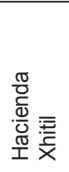 & 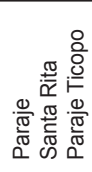 \\
\hline 윯 & $\underset{\infty}{\stackrel{\infty}{\infty}}$ & $\underset{\infty}{\infty}$ & 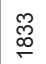 & $\underset{\infty}{\stackrel{ \pm}{\infty}}$ & & 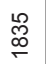 & $\underset{\underset{\infty}{\infty}}{\stackrel{\Sigma}{\infty}}$ & 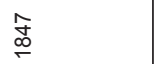 & 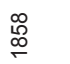 & $\begin{array}{l}\stackrel{\infty}{\stackrel{\infty}{\infty}} \\
\stackrel{\infty}{\infty}\end{array}$ & $\begin{array}{l}\stackrel{0}{\circ} \\
\stackrel{\infty}{\rightleftharpoons}\end{array}$ & $\underset{\infty}{\mathbb{N}}$ \\
\hline 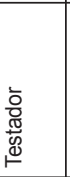 & $\begin{array}{l}\frac{}{\text { क }} \\
\text { U } \\
\text { 임 } \\
\text { d } \\
0\end{array}$ & 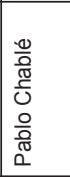 & 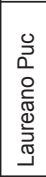 & 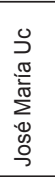 & 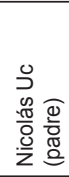 & 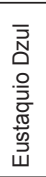 & $\begin{array}{l}\text { 山े } \\
\text { ○ } \\
\text { ○े }\end{array}$ & $\begin{array}{l}\frac{1}{0} \\
0 \\
0 \\
\frac{\pi}{0} \\
0 \\
0 \\
0\end{array}$ & 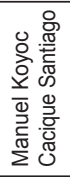 & 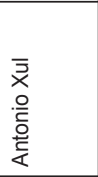 & 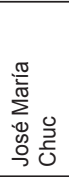 & 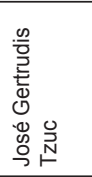 \\
\hline & - & $n$ & $m$ & $\sigma$ & & 10 & 0 & $r$ & $\infty$ & $a$ & 우 & $\mp$ \\
\hline
\end{tabular}




\begin{tabular}{|c|c|c|}
\hline 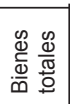 & 吕 & 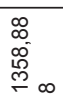 \\
\hline $\begin{array}{l}\frac{\mathscr{\infty}}{\mathscr{d}} \\
\frac{\tilde{\omega}}{0} \\
\infty\end{array}$ & 우 & $\stackrel{\wp}{\longleftarrow}$ \\
\hline 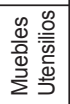 & $\stackrel{\stackrel{N}{ }}{ }$ & $\begin{array}{l}\bar{\infty} \\
\stackrel{\infty}{\circ} \\
\stackrel{-}{\sigma}\end{array}$ \\
\hline 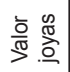 & & $\bar{\infty}$ \\
\hline 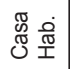 & & \&্ল \\
\hline 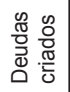 & $\overline{8}$ & \\
\hline 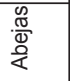 & & \\
\hline 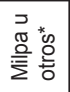 & $\times \quad$ ษ & $\stackrel{\infty}{+}$ \\
\hline 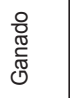 & 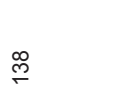 & $\stackrel{N}{\stackrel{N}{2}}$ \\
\hline$\frac{\stackrel{\pi}{\stackrel{\pi}{\pi}}}{\frac{\pi}{\alpha}}$ & 옹 in & 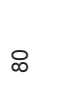 \\
\hline 离 & $\begin{array}{l}\frac{0}{0} \\
\frac{0}{5} \\
\frac{\pi}{\pi} \\
\frac{\pi}{1}\end{array}$ & 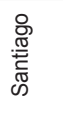 \\
\hline $\begin{array}{r}\frac{0}{0} \\
\frac{\pi}{0} \\
\frac{0}{0} \\
\frac{0}{0} \\
\end{array}$ & 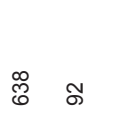 & $\begin{array}{l}\hat{m} \\
\stackrel{m}{m} \\
\bar{m}\end{array}$ \\
\hline $\begin{array}{l}\frac{\pi}{\pi} \\
\frac{\pi}{0} \\
\frac{0}{0} \\
\frac{0}{2}\end{array}$ & 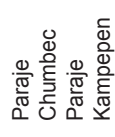 & 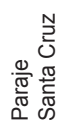 \\
\hline 옳 & 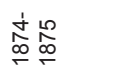 & \begin{tabular}{l}
$\stackrel{9}{0}$ \\
$\infty$ \\
\hdashline
\end{tabular} \\
\hline 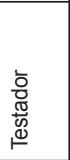 & 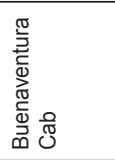 & 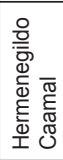 \\
\hline & 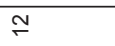 & $\stackrel{m}{\sim}$ \\
\hline
\end{tabular}




\begin{tabular}{|c|c|c|c|c|c|c|c|c|c|}
\hline 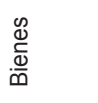 & $\stackrel{\mathbb{Z}}{\sim}$ & $\hat{o}$ & $\begin{array}{l}m \\
\infty \\
o \\
o\end{array}$ & हैं & \begin{tabular}{l}
0 \\
0 \\
0 \\
0 \\
0 \\
\hdashline
\end{tabular} & $\begin{array}{l}0 \\
0 \\
0 \\
0 \\
0\end{array}$ & $\begin{array}{l}\stackrel{*}{0} \\
\stackrel{\sim}{\infty} \\
\stackrel{\sim}{N}\end{array}$ & $\frac{9}{8}$ & , \\
\hline 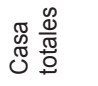 & $m$ & $\stackrel{ }{N}$ & ి్ల & 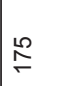 & 웅 & 우 & & ి్ల & \\
\hline $\begin{array}{l}\mathscr{0} \\
\frac{\mathscr{d}}{\pi} \\
\frac{\pi}{0}\end{array}$ & & & & Nָ & in & ஜூ & $\stackrel{\infty}{N}$ & & \\
\hline 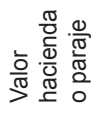 & 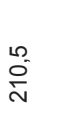 & $\hat{q}$ & 趈 & 龸 & 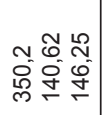 & 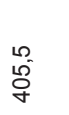 & ஜొ & $\begin{array}{l}0 \\
\text { ठे }\end{array}$ & \\
\hline 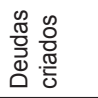 & مـ & & & $\stackrel{1}{\infty}$ & ৪ ঙ্ড় & & $\stackrel{g}{\leftarrow} \underset{ }{\leftarrow}$ & $\infty$ & \\
\hline 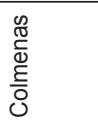 & & $\stackrel{N}{=}$ & & 咅 & 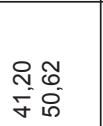 & $\stackrel{\circ}{\square}$ & 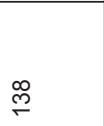 & $\begin{array}{l}+ \\
\dot{q}\end{array}$ & \\
\hline$\frac{\sqrt{2}}{\frac{\underline{2}}{\Sigma}}$ & $\stackrel{\circ}{\circ}$ & $\begin{array}{l}0 \\
\infty \\
\infty^{-}\end{array}$ & ָ̃ & & 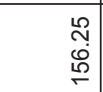 & $\stackrel{2}{\leftarrow}$ & & $\begin{array}{l}\stackrel{N}{0} \\
\stackrel{\infty}{N}\end{array}$ & \\
\hline $\begin{array}{l}0 \\
\frac{0}{0} \\
\frac{\pi}{\pi} \\
0\end{array}$ & $\stackrel{\mathscr{N}}{\sim}$ & 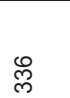 & 总 & 욱 & $\stackrel{ }{N}$ & $\stackrel{\infty}{f}$ & 寻字 & 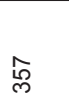 & \\
\hline $\begin{array}{l}\frac{\pi}{\frac{\pi}{5}} \\
\frac{\pi}{0}\end{array}$ & 요 & 8 & $\stackrel{\circ}{\circ}$ & 은 & চి ৪৪ ৪ & ন & 苫 8 & ลิ & \\
\hline $\begin{array}{l}\frac{7}{\pi} \\
\frac{\pi}{0} \\
\frac{0}{2} \\
\frac{0}{2} \\
\frac{1}{2}\end{array}$ & 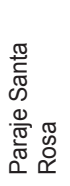 & 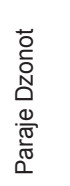 & 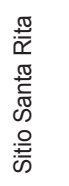 & 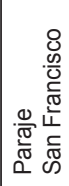 & 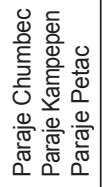 & 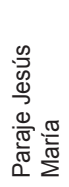 & 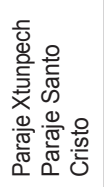 & 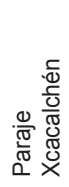 & \\
\hline 彥 & 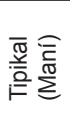 & $\stackrel{\frac{\pi}{\omega}}{\Leftarrow}$ & 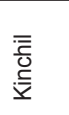 & \begin{tabular}{|l}
.5 \\
츨 \\
우
\end{tabular} & $\begin{array}{l}\frac{\circ}{0} \\
\frac{\pi}{0} \\
\frac{\pi}{10} \\
\text { T) }\end{array}$ & 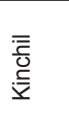 & $\begin{array}{l}\pi \\
\frac{\pi}{0} \\
0 \\
0 \\
\end{array}$ & 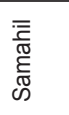 & 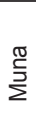 \\
\hline 究 & \begin{tabular}{l}
0 \\
$\stackrel{1}{0}$ \\
\hdashline
\end{tabular} & 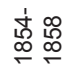 & $\begin{array}{l}\stackrel{0}{\circ} \\
\propto\end{array}$ & $\begin{array}{l}\infty \\
\infty \\
\propto\end{array}$ & $\begin{array}{l}\stackrel{1}{\infty} \\
\stackrel{\infty}{\infty} \underset{\infty}{\infty}\end{array}$ & $\stackrel{\substack{\infty \\
\infty}}{\infty}$ & 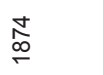 & 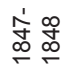 & \\
\hline \multirow[t]{2}{*}{ 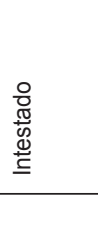 } & 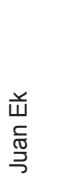 & 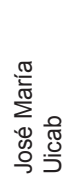 & 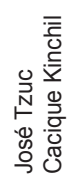 & 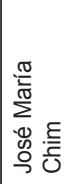 & 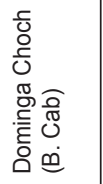 & 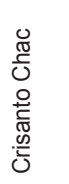 & 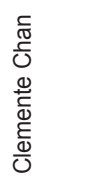 & 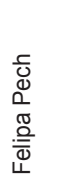 & 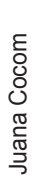 \\
\hline & - & $\sim$ & $m$ & $\theta$ & 10 & 0 & $\lambda$ & $\infty$ & o \\
\hline
\end{tabular}




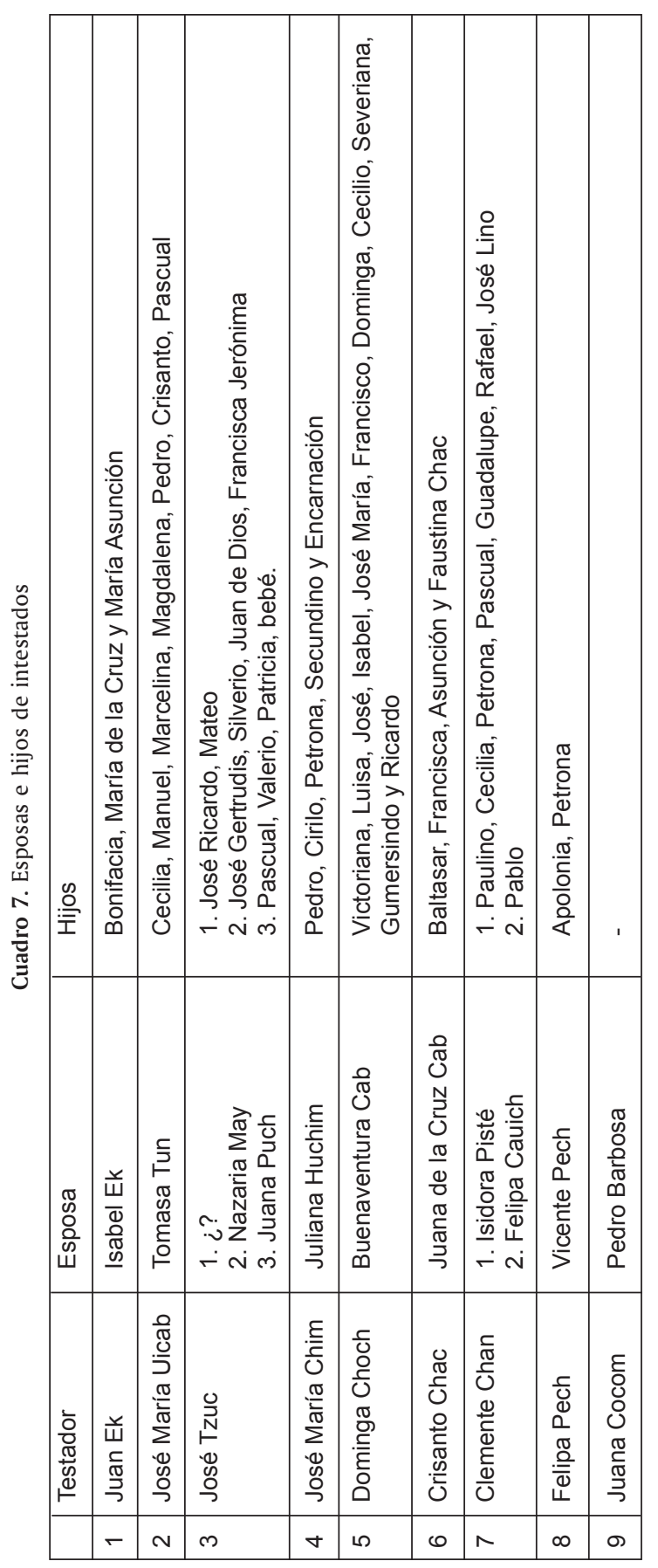




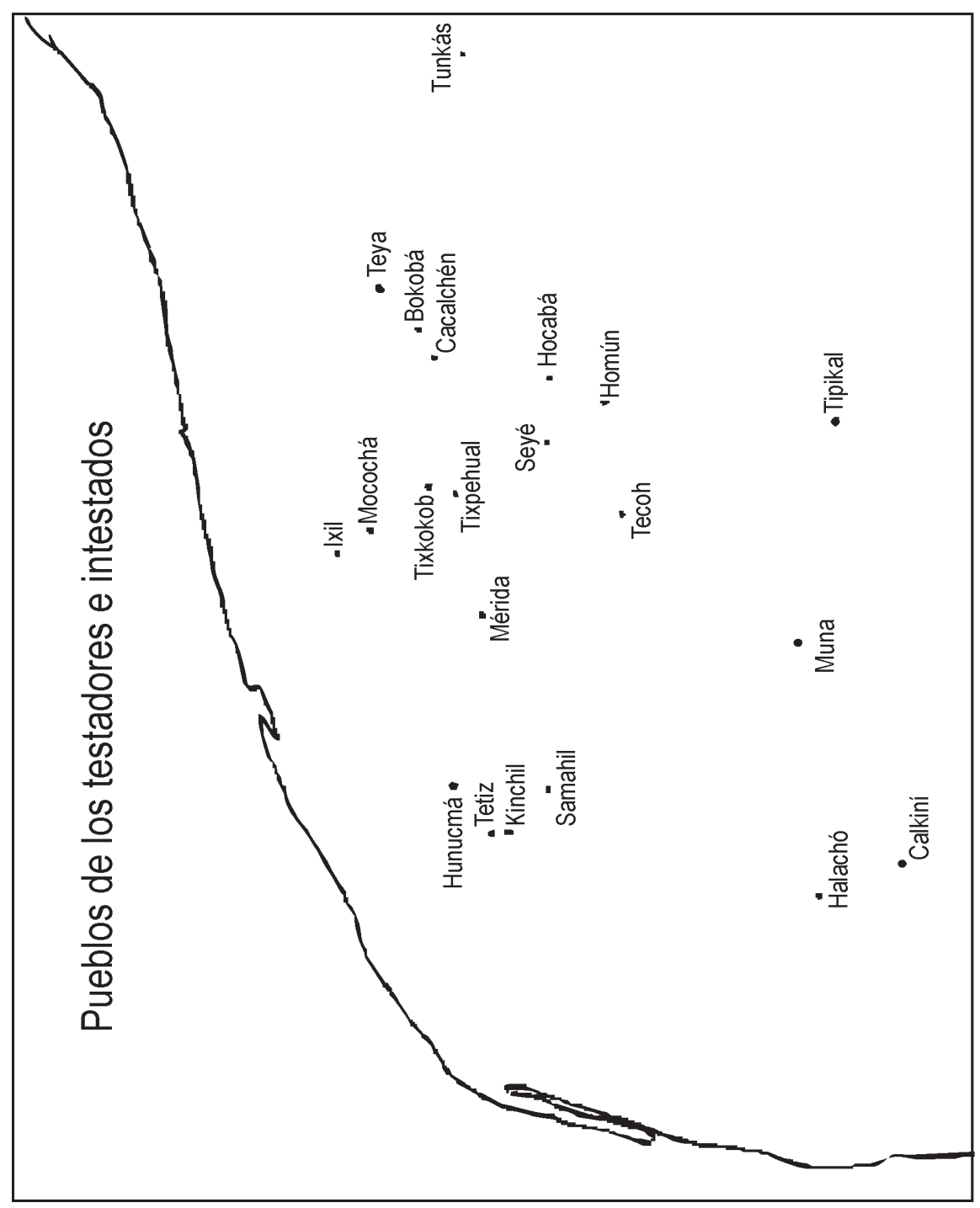




\section{Fuentes}

Todos los expedientes son del Archivo General de Yucatán (AGEY), fondo justicia civil.

\section{$\underline{\text { Sucesiones Testamentarias }}$}

“Testamentaría del finado Pedro Chan", vol. 11, exp. 11. f. 1831-1838.

“Testamentaría de Laureano Puc Nolo”, vol. 16 exp. 23, 1833-1834.

"Testamentaría del indígena José María Uc, quien fuera vecino del pueblo de Tunkas", vol. 20, exp. 5. 1834-1839.

“Testamentaría de Eustaquio Dzul, quien fuera vecino del pueblo de Hocabá, Sotuta", vol. 18, exp. 13. 1835.

“Testamentaría del indígena José María Uc, quien fuera vecino del pueblo de Tunkas", vol. 20, exp. 5, 1834-1839.

"Testamentaría de Bruno Ek quien fuera vecino de Hunucmá", vol. 28 exp. 16, 1841.

“Testamentaría de Pablo Chablé vecino de Tecoh”, vol. 36, exp. 13, 1844-1845.

"Testamentaría de doña Josefa Pech vecina del pueblo de Ixil", vol. 43, exp. 3, 1847.

"Testamentaría del cacique del suburbio de Santiago, Manuel Koyoc", vol. 80, exp. 16, 1858-1862.

“Testamentaría de Antonio Xul”, vol. 84, exp. 14, 1859-1872.

“Testamentaría de María Petrona Pech, vecina que fue del rancho 'Cacalchén' jurisdicción del pueblo de Samahil”, vol. 134, exp. 27, 1867-1868.

“Testamentaría de José María Chuc”, vol. 147, exp. 34, 1869-1870.

“Testamentaría de José Gertrudis Tzuc”, vol. 178, exp. 8, 1872.

“Testamentaría de Hermenegildo Caamal”, vol. 189, exp. 18, 1873-1874.

“Testamentaria de Buenaventura Cab”, vol. 191, exp. 36, 1874-1875.

\section{$\underline{\text { Intestados }}$}

"Sucesión intestada de Nicolás Figueroa, quien fuera vecino del pueblo de Ixil”, vol. 19, exp. 4, 1834-1835.

"Intestado de Juan Ek, vecino que fuera de Tipikal", vol. 41, exp. 28, 1846.

"Diligencias practicadas con motivo del intestado de la finada Felipa Pech, vecina que fuera de Samahil", vol. 44, exp. 21, 1847-1848

"Intestado de José Ucán", vol. 63, exp. 5, 1854-1856.

"Indisposición testamentaria de José María Uicab, vecino del pueblo de Teya", vol. 64, exp. 8, 1854-1858.

"Intestado de Juana Cocom vecina de la hacienda Chasinicche", vol. 61, exp. $5,1854-1867$.

“Intestado de José Tzuc, ex cacique del pueblo de Kinchil”, vol. 117, exp. 5, 1865. 
“Intestado de José María Chim”, vol. 137, exp. 12, 1868.

"Intestado de Dominga Choch", vol. 160, exp. 9, 1870-1873.

"Intestado de Juan Balam”, vol. 158, exp. 61, 1870-1871.

"Intestado de Crisanto Chac de Kinchil”, vol. 186, exp. 19, 1873.

"Intestado de José Clemente Chan y su primera esposa Isidora Pisté", vol. 190, exp. 21, 1874-1877.

\section{BIBLIOGRAFÍA}

Ancona, Eligio

1978 Historia de Yucatán. (1ª ed. 1878). Mérida: Ediciones de la Universidad de Yucatán, 4 vols.

Bracamonte y Sosa, Pedro

2003 Los mayas y la tierra. La propiedad indígena en el Yucatán colonial. México: Centro de Investigaciones y Estudios Superiores en Antropología Social/ Instituto de Cultura de Yucatán.

Chevalier, François

1999 La formación de los latifundios en México. Tierra y sociedad en los siglos XVI y XVII. 3 reimp. México: Fondo de Cultura Económica.

Kellogg, Susan y Matthew Restall

1998 Dead giveaways. Indigenous Testaments of Colonial Mesoamérica and the Andes. Salt Lake City, Utah: The University of Utah Press.

García Ugarte, Marta Eugenia

1992 Hacendados y rancheros queretanos (1780-1920). México: Consejo Nacional para la Cultura y las Artes.

Gómez Serrano, Jesús

$2000 \quad$ Haciendas y ranchos de Aguascalientes. Estudio regional sobre la tenencia de la tierra y el desarrollo agrícola en el siglo XIX. México: Universidad Autónoma de Aguascalientes/Fomento Cultural Banamex.

Guiémez Pineda, Arturo

2005a "El poder de los cabildos mayas y la venta de propiedades privadas a través del tribunal de indios. Yucatán (1750-1821)”, Historia mexicana, 215: 697760 .

2005b Mayas, Gobierno y tierras frente a la acometida liberal en Yucatán. 1812-1847. México: El Colegio de Michoacán/Universidad Autónoma de Yucatán.

Machuca Gallegos, Laura

2007 "Los hacendados yucatecos: pequeña propiedad y movilidad social, 17901809”, Península, II (1) (primavera 2007): 85-102. México: Universidad Na- 
cional Autónoma de México, Centro de Estudios Peninsulares de Ciencias Sociales y Humanidades.

Peniche Moreno, Paola

2007 Ámbitos del parentesco. La sociedad maya en tiempos de la colonia. México: Centro de Investigaciones y Estudios Superiores en Antropología Social.

Restall, Matthew

1995 Life and Death in a Maya Community. The Ixil Testaments of the 1760's. Lancaster, California: Labyrinthos.

1997 The Maya World. Yucatec Culture and Society, 1550-1850. Palo Alto, California: Stanford University Press.

1998 "Interculturation and the Indigenous Testament in Colonial Yucatán", S. Kellogg y M. Restall. Dead Giveaways. Indigenous Testaments of Colonial Mesoamerica and The Andes, pp. 141-162. Salt Lake City, Utah: The University of Utah Press.

Rugeley, Terry

1996 Yucatán's Maya Peasantry. The Origins of the Caste War. Austin, Texas: The University of Texas Press.

Ruz, Mario Humberto

2001 "Propietarias, albaceas, herederas o despojadas. Mujeres en la memoria mortual del mundo maya”, P. Pitarch y J. López García. Los derechos humanos en tierras mayas. Política, representaciones y moralidad, pp. 341-370. Madrid: Sociedad Española de Estudios Mayas.

2002 "De antepasados y herederos: testamentos mayas coloniales", Alteridades, 12 (24): 7-32.

Simard, Jacques

1998 "Liens personnels et milieux sociaux", Réseaux, familles et pouvoirs dans le monde ibérique à la fin de l'ancien régime, pp. 191-230, J. L. Castellano y J.-P. Dedieu (coords.). París: Centre National de la Recherche Scientifique.

2002 "La red de tres indios mercaderes en la Huamanga del siglo xvII, y una hipótesis de trabajo en cuanto al valor de los lazos", Configuraciones y redes de poder, pp. 27-40, M. Bertrand (coord.). Caracas: Tropykos.

Stephens, John Lloyd

2003 Viaje a Yucatán. 1841-1842. Ilustraciones de Frederick Catherwood, introducción de José Ortiz Monasterio. México: Fondo de Cultura Económica.

Van Young, Eric

1992 "Sectores medios rurales en el México de los Borbones: El campo de Guadalajara en el siglo xvII", La crisis del orden colonial. Estructura agraria y rebeliones populares de la Nueva España. 1750-1821. México: Alianza. 